\title{
EFEKTIVITAS MODEL PROBLEM BASED LEARNING PADA PEMBELAJARAN PENDIDIKAN AGAMA ISLAM DALAM MENINGKATKAN MOTIVASI BELAJAR DI SMA NEGERI 1 PANDAAN
}

\author{
Ninin Dwi Novita, Muhammad Nur Hadi, Syaifullah \\ ninindwi@gmail.com,nurhadi@yudharta.ac.id, syaifullah@yudharta.ac.id \\ Universitas Yudharta Pasuruan
}

\begin{abstract}
Abstrac: This study aims to find the effectiveness of the application of the Problem Based Learning model in PAI learning at the top level to generate curiosity and enthusiasm for learning in the PAI learning process.

The problem in this study is the awareness of students about the importance of learning PAI which is very lacking. The purpose of this study was to determine whether PAI learning using a problem based learning model with mind map methods and cooperative learning was more effective when compared to PAI learning which only used other conventional methods.

The sample of this study was 89 students consisting of class XI MIA 1, XI MIA 5, MIA 7 and IS 3 which were taken randomly. With simple random sampling technique. Data collection is done using (1) Questionnaire method, which is a method for collecting data using statements, (2) Documentation Method, which is looking for data about things or variables in the form of notes, transcripts, books and so on.

This study aims to (1) find out the application of the Problem Based Learning model for high school class XI on Islamic Education subjects, (2) find out the effectiveness of the Problem Based Learning model in increasing the learning motivation of high school class XI students in Islamic Education subjects, and ( 3 ) knowing the inhibiting factors and solutions in applying the Problem Based Learning model.

This study uses a quantitative approach. The method used is field research with the design of the pretest and posttest control group design. With the results of the pretest and posttest questionnaire we used the t-test calculation by comparing the results of the $t$ test with $t$ table.
\end{abstract}

Keywords: Effectiveness, Problem Based Learning Model, Learning Motivation 


\section{PENDAHULUAN}

Pendidikan karakter yang ditekan di dalam kurikulum pendidikan terbaru memiliki kaitan erat dengan mata pelajaran Pendidikan Agama Islam. "Membangun dan membekali peserta didik sebagai generasi emas Indonesia tahun 2045 dengan jiwa pancasila dan pendidikan karakter yang baik guna menghadapi dinamika perubahan di masa depan". ${ }^{1}$

Dalam pembelajaran Pendidikan Agama Islam memiliki materi yang hampir sama mulai dari tingkat dasar sampai tingkat lanjut, dimana dalam kajian dan materi saja yang memiliki bobot dan penekanan yang berbeda. Dengan adanya pengulangan materi jika tidak didampingi dengan model dan penekanan pencapaian yang berbeda dan dikemas, disesuaikan dengan tingkat kemampuan peserta didik maka akan menimbulkan kurangnya pemahaman, tingkat minat dan motivasi belajar peserta didik. Dengan adanya masalah tersebut peneliti mencoba menggunakan Model Problem Based Learning agar dapat merubah pemikiran tentang Pendidikan Agama Islam yang terkesan membosankan. Sehingga peneliti berharap dengan adanya penelitian ini maka pendidik dapat memcapai target kurikulum terbaru yang menekankan pada penguatan pendidikan karakter.

Pendidikan memiliki peran penting dalam menciptakan masyarakat yang cerdas, damai, terbuka dan demokratis. Salah satu tujuan bangsa Indonesia yang tertuang dalam pembukaan UUD 1945 adalah mencerdaskan kehidupan bangsa. Pendidikan merupakan kebutuhan yang mendasar bagi setiap manusia. Oleh karena itu proses pembelajaran harus sesuai dengan materi yang akan disampaikan agar dapat dipahami dengan baik khususnya di sekolah dan lembaga-lembaga kependidikan. Yang disesuaikan dengan tujuan pendidikan yakni mengembangkan potensi peserta didik agar menjadi manusia yang beriman dan bertaqwa kepada Tuhan Yang Esa, berakhlak mulia, sehat, berilmu, cakap, kreatif, mandiri, dan menjadi warga Negara yang demokratis serta bertanggungjawab. ${ }^{2}$

Pendidikan di sekolah atau lembaga pendidikan merupakan pendidikan yang dilaksanakan melalui proses interaksi antara pendidik dan peserta yang berlangsung secara terus menerus. Dalam upaya meningkatkan kualitas pendidikan banyak aspek yang mempengaruhi kualitas pendidikan. Kegiatan pembelajaran adalah interaksi antara pendidik dan peserta didik

\footnotetext{
${ }^{1}$ Perpres Nomor 87 Tahun 2017 pasal 2

${ }^{2}$ Sisdiknas tahun 2003 UU No. 20 Pasal 3
} 
meliputi secara langsung ataupun tidak langsung, misalnya melalui media, televisi (TV), komunikasi sosial, dan internet. Kegiatan pembelajaran bertujuan untuk meningkatkan prestasi belajar. Dimana prestasi belajar dianggap meningkat apabila pendidik dapat menumbuhkan minat belajar terhadap peserta didik, sehingga kegiatan belajar mengajar (proses pembelajaran) dapat secara aktif, kreatif, dan menyenangkan. Sehingga peran pendidik sangat penting dalam menentukan pendekatan yang tepat agar kegiatan belajar mengajar (proses pembelajaran) dapat berjalan lancar. Kegiatan pembelajaran menurut teori merupakan proses pendidikan yang memberikan kesempatan kepada peserta didik untuk mengembangkan potensi mereka menjadi kemampuan yang semakin lama semakin meningkat dalam sikap, pengetahuan, dan keterampilan yang diperlukan dirinya untuk hidup dan untuk bermasyarakat, berbangsa, serta berkontribusi pada kesejahteraan hidup umat manusia. ${ }^{3}$ Oleh karena itu, kegiatan pembelajaran diarahkan untuk memberdayakan semua potensi peserta didik menjadi kompetensi yang diharapkan.

Dalam Lampiran Peraturan Menteri Pendidikan dan Kebudayaan Nomor 22 Tahun 2016 tentang Standar Proses Pendidikan Dasar dan Menengah dinyatakan bahwa: Proses pembelajaran pada satuan pendidikan diselenggarakan secara interaktif, inspiratif, menyenangkan, menantang, memotivasi peserta didik untuk berpartisipasi aktif, serta memberikan ruang yang cukup bagi prakarsa, kreativitas, dan kemandirian sesuai dengan bakat, minat, dan perkembangan fisik serta psikologis peserta didik. Untuk itu setiap satuan pendidikan melakukan perencanaan pembelajaran, pelaksanaan proses pembelajaran serta penilaian proses pembelajaran untuk meningkatkan efisiensi dan efektivitas ketercapaian kompetensi lulusan. ${ }^{4}$

Pendekatan pembelajaran dapat diartikan sebagai titik tolak atau sudut pandang kita terhadap proses pembelajaran, yang merujuk pada pandangan tentang terjadinya suatu proses yang sifatnya masih sangat umum, di dalamnya mewadahi, menginspirasi, menguatkan, dan melatari metode pembelajaran dengan cakupan teoritis tertentu. Dari pengertian pendekatan diatas maka kegiatan belajar mengajar pada kurikulum 2013 menekankan bahwa pembelajaran berkaitan dengan pendekatan dimana pendekatan

\footnotetext{
${ }^{3}$ Peraturan Menteri Pendidikan dan Kebudayaan Republik Indonesia, Lampiran IV Nomor 81 A tahun 2013

4 Kementerian Pendidikan dan Kebudayaan, Panduan Pembelajaran Untuk Sekolah Menengah Pertama.(Jakarta:2016) hlm 16
} 
tersebut harus berpusat kepada peserta didik. Dalam pelaksanaanya maka dibutuhkan suatu model yang dapat mendukung kegiatan belajar mengajar. Metode sendiri memiliki arti langkah operasional dari strategi pembelajaran yang dipilih dalam mencapai tujuan belajar. Menurut kamus Purwadarminta (1976) metode adalah cara yang telah teratur dan terfikir baik-baik untuk mencapai sesuatu maksud. Menurut Kamus Besar Bahasa Indonesia, metode adalah cara kerja yang bersistem untuk memudahkan pelaksanaan suatu kegiatan guna untuk mencapai tujuan yang ditentukan.

Dari pengertian diatas dan perkembangan kurikulum pendidikan. Salah satu pendekatan yang sesuai dengan kurikulum terbaru yaitu pendekatan Problem Based Learning. Problem based learning sendiri memiliki tujuan dan manfaat melatih perkembangan pola pikir peserta didik yang kreatif dan inovatif.

Model Problem Based Learning berpusat pada siswa sehingga sangat cocok dengan kurikulum pendidikan saat ini. Dalam proses kegiatan pembelajaran khususnya di dalam model Problem Based Learning sendiri memiliki beberapa strategi dan metode. Dimana dalam pencapaian kurikulum pendidikan khususnya di mata pelajaran Pendidikan Agama Islam pendidik dituntut untuk dapat mengkontruksikan pendekatan ini dengan metode, media dan strategi tersendiri. Di dalam pelaksanaan kegiatan belajar mengajar seorang pendidik harus dapat menggunakan teknik dan taktik yang sesuai dengan karakteristik peserta didiknya serta fasilitas yang dimiliki lembaga tersebut.

Sehingga dapat disimpulkan bahwa Model Problem Based Learning ialah suatu pendekatan yang membantu seorang pendidik untuk menyampaikan ilmu pengetahuan terhadap peserta didik sesuai dengan kurikulum pendidikan terbaru. Dalam pendekatan ini ada banyak metode strategi media dan taktik seorang pendidik dalam penggunaanya dan prosedur pelaksanaan dalam kegiatan belajar mengajar. Pada intinya pembelajaran yang diharapkan yakni sebagaimana dimaksud meliputi mengamati, menanya, mencoba, mengolah, menyajikan, menyimpulkan, dan mencipta untuk semua mata pelajaran.

Dalam pembelajaran Pendidikan Agama Islam sendiri pendekatan ini memiliki tujuan yang sesuai dengan kurikulum dikarenakan dalam kurikulum 2013 Pendidikan Agama Islam ditekankan untuk dapat memperbaiki dan membuat karakter-karakter peserta didik yang mandiri, kreatif cerdas serta berakhlak yang baik. 


\section{TUJUAN PENELITIAN}

1. Mengetahui langkah-langkah proses kegiatan pembelajaran Pendidikan Agama Islam dengan menggunangkan model Problem Based Learning.

2. Mengetahui efektivitas model Problem Based Learning dalam pembelajaran Pendidikan Agama Islam dalam meningkatkan motivasi belajar peserta didik di SMA Negeri 1 Pandaan.

\section{KAJIAN TEORI}

\section{Problem Based Learning}

Dari segi sejarah Problem Based Learning itu dipusatkan pada peserta didik yang dihadapkan pada suatu masalah. Sementara pada subjek Based Learning pendidik menyampaikan pengetahuan kepada peserta didik.

Problem Based Learning adalah pembelajaran yang menggunakan masalah nyata dalam kehidupan sehari-hari (otentik) yang bersifat terbuka untuk diselesaikan oleh peserta didik untuk mengembangkan keterampilan berpikir, keterampilan menyelesaikan masalah, keterampilan sosial, keterampilan untuk belajar mandiri dan membangun atau memperoleh pengetahuan baru.

Menurut Muslimin dalam Boud dan Felleti pembelajaran Problem Based Learning adalah suatu pendekatan untuk membelajarkan peserta didik untuk mengembangkan keterampilan berpikir dan keterampilan memecahkan masalah, serta menjadi peserta didik yang mandiri. Problem Based Learning tidak dirancang untuk membantu pendidik memberikan informasi yang sebanyak-banyaknya, akan tetapi pembelajaran ini dikembangkan untuk membantu peserta didik mengembangkan kemampuan berpikir, memecahkan masalah, keterampilan intelektual, belajar berbagai pengalaman nyata, dan menjadi pembelajaran yang mandiri.

Problem Based Learning merupakan pembelajaran dengan pendekatan pembelajaran peserta didik sebagai pusat pembelajaran. Dengan begitu pembelajaran peserta didik pada masalah autentik sehingga peserta didik dapat menyusun pengetahuannya sendiri, menumbuhkan keterampilan dalam memecahkan masalah, membuat hipotesa, peserta didik lebih mandiri, meningkatkan rasa percaya diri peserta didik. 
Dari kesimpulan dan pengertian diatas dapat disimpulkan bahwa Problem Based Learning ialah suatu pendekatan yang mendorong peserta didik untuk belajar bagaimana belajar, bekerja secara berkelompok untuk mencari solusi dari permasalahan. Masalah yang diberikan memiliki tujuan untuk menimbulkan rasa ingin tahu dan memiliki rasa semangat untuk mempelajari suatu masalah tersebut.

\section{Langkah-langkah model Problem Based Learning}

Dalam penerapan Problem Based Learning memiliki langkahlangkah sebagai berikut: ${ }^{5}$
a. Orientasi peserta didik terhadap masalah.
b. Mengorganisasikan peserta didik untuk belajar.
c. Pendidik membimbing pencarian data suatu masalah.
d. Mengembangkan dan menyajikan hasil karya.
e. Menganalisis dan mengevaluasi.

Langkah-langkah dalam penerapan Problem Based Learning yakni:

a. Klarifikasi masalah.

1) Pendidik menyajikan fenomena yang mengandung masalah yang sesuai dengan kompetensi dasar atau indikator, berbentuk gambar, teks, video dan lain sebagainya

2) Peserta didik melakukan identifikasi terhadap paparan yang disajikan pendidik untuk menentukan masalah dari paparan tersebut

3) Klarifikasi masalah yang ditemukan peserta didik terhadap pendidik

b. Brainstorming.

1) Peserta didik melakukan identifikasi dengan segala fasilitas yang disediakan pendidik

2) Pendidik menfasilitasi peserta didik untuk mengklarifikasi fakta, konsep, procedure dan kaidah dari masalah yang ditemukan

3) Peserta didik melakukan brainstorming dengan cara sharing informasi, klarifikasi informasi dan data.

\footnotetext{
${ }^{5}$ Hosnan, Pendekatan Saintifik dan Kontekstual dalam Pembelajaran Abad 21 Kunci Sukses Implementasu Kurikulum 2013. (Jakarta:Ghalia Indonesia:2014) hlm 24 
c. Pengumpulan data dan informasi.

1) Peserta didik melakukan pengumpulan data

2) Peserta didik secara mandiri melakukan pengolahan data untuk dijadikan solusi masalah

3) Berbagi informasi dan berdiskusi untuk menemukan solusi penyelesaian masalah

4) Presentasi hasil penyelesaian masalah

5) Refleksi.

\section{HIPOTESIS}

$\mathrm{H}_{\mathrm{o}}=$ Penerapan model problem based learning tidak efektif digunakan pada pembelajaran pendidikan agama islam dalam meningkatkan motivasi belajar.

$\mathrm{H}_{\mathrm{a}}=$ Penerapan model problem based learning efektif digunakan pada pembelajaran pendidikan agama islam dalam meningkatkan motivasi belajar.

\section{PEMBAHASAN}

\section{Langkah-langkah model Problem Based Learning}

\begin{tabular}{|l|l|l|}
\hline No. & \multicolumn{1}{|c|}{ Indikator } & \multicolumn{1}{c|}{ Kegiatan Pembelajaran } \\
\hline 1. & Mengorientasi & $\begin{array}{l}\text { Peserta didik mengamati suatu } \\
\text { permasalahan yang terkait dengan } \\
\text { materi }\end{array}$ \\
\hline 2. & $\begin{array}{l}\text { Mengorganisasikan } \\
\text { kegiatan }\end{array}$ & $\begin{array}{l}\text { Guru membantu mengorganisasikan } \\
\text { belajar yang berhubungan dengan materi }\end{array}$ \\
\hline 3. & $\begin{array}{l}\text { Membimbing } \\
\text { penyeledikan } \\
\text { kemandirian dan } \\
\text { kelompok }\end{array}$ & $\begin{array}{l}\text { Peserta didik mengumpulkan data dan } \\
\text { informasi dari berbagai literature dan } \\
\text { guru membimbing kegiatan setiap } \\
\text { langkah }\end{array}$ \\
\hline 4. & $\begin{array}{l}\text { Mengembangkan dan } \\
\text { menyajikan hasil }\end{array}$ & $\begin{array}{l}\text { Peserta didik menyiapkan laporan } \\
\text { sementara diskusi dan menyampaikan } \\
\text { secara klasikal }\end{array}$ \\
\hline 5. & $\begin{array}{l}\text { Menganalisis dan } \\
\text { evaluasi }\end{array}$ & $\begin{array}{l}\text { Pendidik mengarahkan dan memberi } \\
\text { klarifikasi tentang miskonsepsi }\end{array}$ \\
\hline
\end{tabular}


172 ][ Efektivitas Model Problem Based Learning pada Pembelajaran Pendidikan Agama Islam

\section{Uji T-Tes Paired Two Sample}

t-Test: Paired Two Sample for Means

\begin{tabular}{lrr}
\hline & $\begin{array}{c}\text { sebelum Penerapan } \\
\text { Problem Based } \\
\text { Learning }\end{array}$ & $\begin{array}{c}\text { sesudah Penerapan } \\
\text { Problem Based } \\
\text { Learning }\end{array}$ \\
\hline Mean & 59.51685393 & 63.21348315 \\
Variance & 6.025280899 & 13.82890705 \\
Observations & 89 & 89 \\
Pearson & & \\
Correlation & 0.054999438 & \\
Hypothesized Mean & & \\
Difference & 0 & \\
Df & 88 & \\
$t$ Stat & -8.0323762 & \\
$P(T<=t)$ one-tail & $1.99009 \mathrm{E}-12$ & \\
$t$ Critical one-tail & 1.662354029 & \\
$P(T<=t)$ two-tail & $3.98019 \mathrm{E}-12$ & \\
$t$ Critical two-tail & 1.987289865 & \\
\hline
\end{tabular}

\section{Interpretasi hasil Uji T-Tes Paired Two Sample}

a. Pada tabel Paired Sample Statisti, memuat deskripsi tentang motivasi belajar peserta didik antara sebelum dan sesudah diberikan penerapan pembelajaran Pendidikan Agama Islam dengan menggunkan model problem based learning yang meliputi banyaknya data, mean, variance, dan pearson correlation.

b. Banyak data $\mathrm{N}$ masing-masing peserta didik antara sebelum dan sesudah diberikan model problem based learning $=89$, rata-rata (mean) tingkat motivasi belajar peserta didik sebelum diberikan model problem based learning $=59,52$ dan nilai rata-rata output sesudah penerapan model problem based learning sebesar 63,21, variance tingkat motivasi belajar peserta didik sebelum diberikan model problem based learning sebesar 6,02 dan nilai variansi sesudah penerapan model problem based learning sebesar 13,8, dan pearson correlation sebesar 0,055 . 
c. Berdasarkan perbandingan rata-rata (mean) tingkat motivasi belajar peserta didik dalam pembelajaran Pendidikan Agama Islam antara sebelum diberikan model problem based learning $=59,52$ dan sesudah penerapan model problem based learning sebesar 63,21. Hal itu berarti menunjukan bahwa terdapat peningkatan yang signifikan motivasi belajar peserta didik dalam pembelajaran Pendidikan Agama Islam.

d. Pada tabel paired sample statistic terdapat pearson correlation sebesar 0,055 .

e. Pada tabel Paired Two Sample for Means memuat data hasil analisis uji-t dua sampel berpasangan yang meliputi t hitung dan signifikansi

Berdasarkan data di atas maka dapat dilakukan pengujian hipotesis dengan cara sebagai berikut:

Dengan cara membandingkan t-hitung dangan t tabel

- Jika t hitung $>\mathrm{t}$ tabel, maka Ho ditolak

- Jika t hitung < t tabel, maka Ho diterima

Untuk melihat nilai $\mathrm{t}$ tabel maka didasarkan pada derajat kebebasan (dk), yang besarnya adalah $\mathrm{N}-1$, yaitu $89-1=88$, berdasarkan hasil analisis uji $\mathrm{t}$ dua sampel berpasangan, maka dapat diperoleh hasil sebagai berikut: $t$ hitung lebih besar dari $t$ tabel $(8,03>1$, 66), maka Ho di tolak yang artinya model problem based learning efektif dalam meningkat motivasi peserta didik dalam pembelajaran Pendidikan Agama Islam.

\section{KESIMPULAN}

1. Penerapan model problem based learning di kelas XII MIA 1, MIA 5, MIA 7 dan IS 3 dilaksanakan melalui tiga tahap, yaitu perencanaan, pelaksanaan dan evaluasi. Dan dari ketiga tahapan itu semuanya berjalan dengan baik.

2. Efektifitas penggunaan model problem based learning dalam pembelajaran Pendidikan Agama Islam dapat dilihat dari efektifitas proses. Efektifitas dari segi proses dapat dilihat dari pengorganisasian materi, meningkatnya antusias dan motivasi peserta didik dalam mengikuti pelajaran, kemampuan siswa dalam memecahkan persoalan yang diberikan oleh pendidik, serta terjadinya pembelajaran interaksif. Dan berdasarkan analisis uji $\mathrm{t}$ dua sampel berpasangan dapat disimpulkan bahwa model problem based learning efektif digunakan pada 
174 ][ Efektivitas Model Problem Based Learning pada Pembelajaran Pendidikan Agama Islam

pembelajaran pendidikan agama islam dalam meningkatkan motivasi belajar, sehingga motivasi belajar peserta didik antara sebelum dan sesudah diberikan model problem based learning adalah berbeda. Berdasrakan perbandingan rata-rata (mean) tingkat motivasi belajar peserta didik sebelum diberikan model problem based learning lebih sedikit dari nilai rata-rata sesudah penerapan model problem based learning, dengan hal itu berarti memiliki peningkatan yang signifikan motivasi belajar peserta didik dalam pembelajaran Pendidikan Agama Islam. Maka, model Problem Based Learning sangat efektif dalam upaya meningkatkan motivasi belajar peserta didik dalam pembelajaran Pendidikan Agama Islam.

\section{DAFTAR PUSTAKA}

Arikunto, Suharsimi, Dr. (1993). Prosedur Penelitian, Suatu Penekatan Praktek. Jakarta: PT. Rineka Cipta

Arikunto, Suharsimi, Dr. (2003). Manajemen Penelitian. Jakarta: PT. Rineka Cipta

Arikunto, Suharsimi, Dr. (2012). Dasar-Dasar Evaluasi Pendidikan. Jakarta: Bumi Aksara.

Baharudin, Esa Nur W. (2008). Teori Belajar dan Pembelajaran. Jogjakarta: Ar Ruzz Media.

Departemen Agama RI. (2002). Metodologi Pendidikan Agama Islam. Jakarta: Direktorat Jenderal Kelembagaan Agama Islam.

Haitami \& Syamsul. (2012). Studi Ilmu Pendidikan Islam. Yogyakarta: Ar Ruzz

Hosnan. (2014). Pendekatan Saintifik dan Kontekstual dalam Pembelajaran Abad 21 Kunci Sukses Implementasu Kurikulum 2013. Jakarta: Ghalia Indonesia.

Kebudayaan, K. P. (2013). Pandaun Penguatan Proses Pembelajaran Sekolah Menengah Pertama.

NUH, M. (2013). Peraturan Menteri Pendidikan Dan Kebudayaan Republik Indonesia. Jakarta.

Nurihsan, S. Y. (2005). Landasan Bimbingan dan Konseling. Bandung: Remaja Rosdakarya.

Peraturan Menteri Pendidikan Nasional RI. (2007). Standar Proses Untuk Satuan Pendidikan Dasar dan Menengah. Jakarta: Depdikbud. 
Poerwodarminto W.J.S. (1990). Kamus Umum Bahasa Indonesia. Jakarta : Balai Pustaka.

Rifaei. (1978). Ilmu Fiqih Lengkap. Semarang: CV. Toha Putra. Ramayulis. (2006). Ilmu Pendidikan Islam. Jakarta: Kalam Mulia.

Rosalia, S. (2005). Analisis Statistik Menggunakan Aplikasi Excel. Bandung: Alfabeta.

Sadjiman, A., dkk. (2012). Media Pendidikan Pengertian, Pengembangan, dan Pemanfaatannya. Jakarta: PT Raja Grafindo Persada.

Suprihatiningrum, J. (2014). Strategi Pembelajaran Teori dan Aplikasi. Jogyakarta: Ar Ruzz Media.

Syafiful Bahri Djamarah dan Azwan Zain. (2002). Strategi Belajar Mengajar. Jakarta: PT Reneka Cipta.

Wijayani, N. A. (2013). Desain Pembelajaran Pendidikan. Yogyakarta: ArRuzz Media. 
176 ][ Efektivitas Model Problem Based Learning pada Pembelajaran Pendidikan Agama Islam

Nurnal al-Murabli, Volume 4 Namar 2, Jumi 2019 